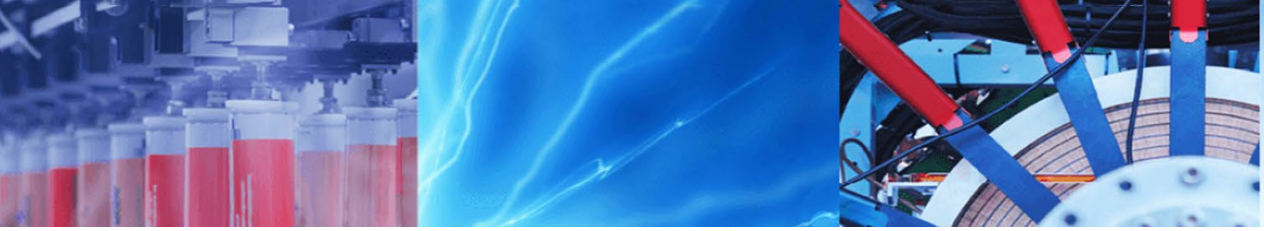

Research Article

\title{
Experiment and modelling of the strain-rate-dependent response during in vitro degradation of PLA fibres
}

\author{
Anurag Singh ${ }^{1,2}$ (D) Rui Miranda Guedes ${ }^{1,2,3} \cdot$ Diana Paiva $^{4} \cdot$ Fernão D. Magalhães ${ }^{4}$
}

Received: 20 September 2019 / Accepted: 4 January 2020 / Published online: 10 January 2020

(c) Springer Nature Switzerland AG 2020

\begin{abstract}
Polylactic acid (PLA) fibres present, in their pristine state, a strain-rate-dependent behaviour. Their mechanical properties evolve during in vitro biodegradation. Tensile tests of PLA fibres are performed at five different strain rates 0.0001, 0.001, $0.01,0.05$ and $0.1 / \mathrm{s}$ and at seven degradation stages, $0,20,40,60,90,120$ and 150 days in a phosphate buffer solution at constant temperature at $37^{\circ} \mathrm{C}$. The mechanical response is modelled using a modified three-element standard solid model proposed for polymers under finite deformations range. Observations on experimental data lead to the conclusion that the viscous parameters $\eta_{1}$ and $\eta_{2}$ are strain rate dependent, and they vary from 10,762/3202 (N/m s) at the lowest strain rate of $0.0001 / \mathrm{s}$, and $12.2 / 9.1(\mathrm{~N} / \mathrm{m} \mathrm{s})$ at the highest strain rate of $0.1 / \mathrm{s}$ for $\eta_{1}$ and $\eta_{2}$, respectively, thus, depicting the shear-thinning phenomena with the increase in strain rate. Whereas stiffness parameters $C_{1}$ and $C_{2}$ are degradation dependent, they vary from 21.6/13.7 (N/m) for undegraded PLA fibres and 9.7/5.4 (N/m) for 150 days degraded PLA fibres for $C_{1}$ and $C_{2}$, respectively. Decay of stiffness parameters during biodegradation follows an exponential law. The model will be useful to design and develop new fibrous structures for ligament augmentation devices. It could contribute to develop better devices with improved mechanical performance helping those patients in need to repair the ligament tissue.
\end{abstract}

Keywords Hydrolytic degradation · Mechanical behaviour evolution · PLA fibres · Nonlinear viscoelasticity · Tissue engineering

\section{Introduction}

Polymers stand for the largest class of biomaterials; they can be derived either from natural or synthetic process. Aliphatic polyesters are the most studied category of biodegradable polymers as they are biocompatible, biodegradable, and have good mechanical properties. Moreover, degradation products formed by hydrolytic and enzymatic cleavage lead to the formation of $a$-hydroxy acids, which is assimilated within the body. The ease of tailoring their degradation profile has led to their popularity over natural polymer. Due to all these advantages, apart from being considered as a material for the ligament augmentation device (LAD), they are already being used in various medical applications such as surgical sutures, fixation screws, internal bone fixation, drug delivery, medical devices [1, 2]. Use of these biodegradable polymers eliminates the need for a revision surgery for removal of the medical device. Another advantage is being able to control degradation rate by altering the macromolecular structure of polymers. However, primary

Electronic supplementary material The online version of this article (https://doi.org/10.1007/s42452-020-1964-4) contains supplementary material, which is available to authorized users.

$\triangle$ Anurag Singh, anuragsvr@gmail.com | 'Department of Mechanical Engineering (DEMec), Faculty of Engineering, University of Porto (FEUP), Rua Dr Roberto Frias, 4200-465 Porto, Portugal. ${ }^{2}$ INEGI - Laboratory of Optics and Experimental Mechanics, Rua Dr. Roberto Frias $\mathrm{s} / \mathrm{n}, 4200-465$ Porto, Portugal. ${ }^{3}$ LABIOMEP - Porto Biomechanics Laboratory, University of Porto, 4200-450 Porto, Portugal. ${ }^{4} \mathrm{LEPABE}$, Faculdade de Engenharia, Universidade Do Porto, Rua Dr. Roberto Frias, 4200-465 Porto, Portugal. 
concern behind the design of medical device for orthopaedic applications is the evolution of load-bearing capability during degradation [3-6]. Biodegradable polymers obtained from renewable resources have attracted much attention in recent years. This new interest results from global environmental respect awareness and the fossil depletion problem.

Selection of the material is important in the design and development of the medical device in tissue engineering. The primary concern is sustainability of strength of material over the period of interest, and this can be assessed through controlled environmental degradation in a balanced salt solution [7]. Modelling the behaviour of biodegradable medical device after the implant poses another big challenge. While engineering medical devices, biodegradable material cannot be assumed as an elastic material; these materials undergoes large deformation beyond elastic limit and follows a nonlinear viscoelastic mechanical behaviour. The viscoelastic response of solid can be decomposed into an instantaneous or elastic response and into a delayed or time-dependent response [8]. Upon removing the load, the elastic response is recovered instantaneously, while the time-dependent response is gradually recovered provided enough time [8]. Full recovery is expected at low levels of stress, on higher stress levels viscoplasticity comes into play and leads to the permanent deformation [9-13]. Therefore, a thorough understanding of the inelastic properties of the material is necessary to characterize the biodegradable polymers.

For the first time, the complete stress-strain curves of PLA yarns measured for five different strain rates, at seven degradation stages, from 0 to 150 days, were casted into a simple but effective nonlinear viscoelastic model. Specimens supplied by Trevira (Germany) as multifilament texturized yarns composed of 32 PLA fibres with a diameter of $20 \mu \mathrm{m}$ (167 dtex f32) were subjected to several degradation stages in a phosphate buffer solution at $37^{\circ} \mathrm{C}$. A modified three-element standard solid model was used to represent the strain-rate-dependent response of PLA yarns at large deformations. The viscous parameters remained constant during degradation, but they exhibited strain rate dependency. On the contrary, stiffness parameters varied during degradation time, but they remained constant at strain rate variations. After these observations, the model was constructed, and it proved able to capture consistently all experimental data.

\section{Effect of hydrolytic degradation on the mechanical properties}

PLA is one of the aliphatic biodegradable polymers which present numerous possibilities to be used as a biodegradable material for orthopaedic applications in tissue engineering. PLA is derived from renewable source like corn and rice (carbohydrates), followed by fermentation of these carbohydrates to obtain the lactic acid; after that it is dehydrated to obtain the lactides $[14,15]$. These lactides undergo ring-opening polymerization to synthesize PLA, which is an aliphatic polyester having semi-crystalline structure [16]. Aliphatic polyester contains an ester bond in its linkage, and the degradation mechanism of aliphatic polyester microspheres is hydrolytic $[17,18]$. Thus, depending upon molecular weight, crystallinity, and shape, it degenerates completely into lactic acid in a period of 10 months to 4 years [19]. The hydrolytic degradation of PLA promoted by water molecules leads to the formation of carboxylic group and hydroxyl group $[15,20]$. It degrades further into carbon dioxide and water in the presence of aerobic bacteria, which are easily assimilated within the body $[15,20]$, thereby making it a suitable candidate for medical devices.

Hayman et al. [21] measured the effect of PLA hydrolytic degradation on the mechanical properties, observing an increase in degradation upon increasing the applied static or dynamic loading during hydrolysis. Göpferich [22] observed that PLA takes more time for complete degradation on comparison with loss of tensile strength, with steric hindrance being one of the factors for slow degradation. In case of sutures and stents, implant should possess sufficient physical and mechanical properties, i.e. strength, stiffness and ductility (extensibility) close to that of the tissue under consideration [23]. Mechanical response of PLA and other bioresorbable polymers is highly nonlinear due to a strong dependence on temperature, molecular weight, molecular orientation, crystallinity and physical ageing [24].

Degradation affect mechanical properties such as elastic modulus, tensile strength and elongation, which is important for understanding the long-term behaviour; medical devices for orthopaedic application should bear the load throughout their working life. Therefore, understanding the evolution of mechanical properties during degradation becomes important for lifetime prediction of medical device $[25,26]$. Long-term mechanical behaviour of biodegradable polymers can be analysed by accelerating the tests, either by imposing large stress or strain or by performing experiments at elevated temperatures. Previous studies studied how the time-dependent behaviour is affected by degradation? Those were merely experimental using $b$-tricalcium phosphate (TCP)/poly (L-lactic acid) (PLLA) composites in PBS [27] and using experimental data of biodegradable triblock copolymer PLA- $b$-PEG- $b$-PLA to obtain a quasi-linear viscoelastic model adapted to degradation [28]. The previous reported cases use'rigid' specimens in small strain domain. On the other hand, numerous studies measured the molecular weight variation with 
hydrolysis time. Remarkably, very few studied the impact of these changes on the mechanical properties [29]. Weir et al. [30] for the PLA and Vieira et al. [31] for PLA-PCL blend experimentally established a direct correlation between strength decay and molecular weight decrease, which can be explained by an exponential law as in Eq. (1).

$P_{\mathrm{n}}=P_{0} \mathrm{e}^{-\mu t}$

where $P=M_{\mathrm{n}}$ (number molecular weight), $M_{\mathrm{w}}$ (weighted molecular weight), $E$ (MPa) (Young modulus) or $\sigma_{\mathrm{R}}(\mathrm{MPa})$ (failure stress), $P_{0}$ is the respective initial value and $\mu$ is the decay rate.

Recently, Zhang et al. [32] proposed an interesting three-scale method (microscale, mesoscopic scale and macroscale) to predict strength of bioresorbable polyesters during hydrolytic degradation. The strength was related to molecular weight through a power law given by Eq. (2).

$\frac{\sigma(t)}{\sigma_{0}}=\alpha\left(\frac{M_{\mathrm{n}}(t)}{M_{n 0}}\right)^{\beta}$

where $\sigma_{0}$ and $M_{n 0}$ are the initial strength and molecular weight, $\sigma(t)$ and $M_{\mathrm{n}}(t)$ are the strength and molecular weight at time $t$, respectively and $\alpha, \beta$ are material parameters obtain by experimental calibration. They applied the same equation for amorphous and crystalline phases, with different material parameters. Again, this is a semiempirical approach with parameters obtained from experiments. Curiously, the authors did not consider the stiffness degradation [30-32].

Table 1 shows the results from Weir et al. as molecular weight, elastic modulus and tensile strength decrease with degradation; this evolution is well represented by exponential law as described in Eq. (1). Evolution of tensile strength with degradation is well discussed by Weir et al. and Vieira et al. However, they failed to explain these results in terms of stiffness.
In case of ropes or cords as a load-bearing element, it is important to understand how its basic element, usually a multifilament, behaves before and after degradation [33, 34]. These cords or ropes can be designed as scaffold for artificial tendon or ligament with a structure mimicking the mechanical performance of the natural tissue [34]. PLA fibres can be employed for this purpose to offer gradual transfer of load and subsequently restoring the capabilities of the tendon or ligament $[35,36]$.

As far our knowledge goes, there are no similar published studies on hydrolytic degradation of PLA. Previous works considered the whole stress-strain curve but discarded the strain rate effects [37-39].

This research work comprises the complete stress-strain curves, until failure, of PLA fibres at five different strain rates $0.0001,0.001,0.01,0.05$ and $0.1 / \mathrm{s}$ and at seven degradation stages, $0,20,40,60,90,120$ and 150 days in a phosphate buffer solution (PBS) at constant temperature $\left(37^{\circ} \mathrm{C}\right)$. Again, for the first time, a nonlinear viscoelastic model, with the ability to capture the strain-rate-dependent behaviour of PLA fibres (until failure), was modified to incorporate the hydrolytic damage. The hydrolytic damage was defined through the properties decay, in a similar fashion as it was proposed by Vieira et al. [26]

\subsection{Constitutive modelling}

Materials which display inelasticity are often described by viscoelastic or viscoplastic models, which can be written as a function of stress or strain, as in Eq. (3) below.

$f(\sigma, \varepsilon, \dot{\sigma}, \dot{\varepsilon})=0$.

Several constitutive models have been developed in the past, which are generally expressed through integral or differential equations to model the time-dependent mechanical behaviour of polymers [21, 30, 40-46]. Differential forms are more commonly used to simulate the
Table 1 Results from Weir et al. showing weighted molecular weight, number molecular weight, elastic modulus and tensile strength [30]

\begin{tabular}{lllll}
\hline Degradation time (in days) & $M_{\mathrm{w}}(\mathrm{g} / \mathrm{mol})$ & $M_{\mathrm{n}}(\mathrm{g} / \mathrm{mol})$ & $\begin{array}{l}\text { Young's modulus } \\
E(\mathrm{MPa})\end{array}$ & $\begin{array}{l}\text { Tensile } \\
\text { strength } \\
(\mathrm{MPa})\end{array}$ \\
\hline 0 & & & 64.3 \\
28 & 424,000 & 158,500 & 668.4 & 53.8 \\
70 & 339,000 & 143,000 & 618.4 & 60.3 \\
140 & 309,000 & 120,000 & 625.2 & 23.7 \\
182 & 199,000 & 72,500 & 433 & 36.9 \\
224 & 199,000 & 93,850 & 528.7 & 9.9 \\
266 & 159,000 & 65,800 & 226.5 & 8.2 \\
308 & 133,500 & 53,050 & 284.2 & 1 \\
Degradation rate, $\mu$ (1/day) & 74,900 & 22,500 & - & 0.0077
\end{tabular}


viscoelastic response of the material, and spring and dashpot models have been widely used.

The linear viscoelastic theory is valid in a small strain domain. Below certain stress level, deformation behaviour is approximately linear but with the increase in stress, the material starts showing a nonlinear response [41]. In many applications, the material is subjected to high stress and strains beyond the linear viscoelastic limit, thus exhibiting nonlinear viscoelastic response. If enough time is given, a part of this inelastic deformation shows recovery. Both recoverable and permanent deformations are time dependent $[21,25,30,40,41,47]$.

\subsection{Time-dependent effects}

Experimentally observed stress-strain behaviour in thermoplastic materials is characterized by an initial linearelastic or linear viscoelastic response, and nonlinear and viscoplastic behaviour develops over time [24]. Since the material is in a glassy state, there will always be a stochastic distribution of free volume, energy barriers and shear transformation sites [24]. The sites with the lowest energy barriers have a greater probability of local shear transformation events (local yielding) [24]. As these stresses increase, transformation starts to occur at a meaningful rate causing a nonlinear stress-strain response. During these events, the surrounding material will exert a back stress on the transformed regions, causing a further increase in the activation barrier for viscoplastic flow [24]. When the material is unloaded, these back stresses cause a highly nonlinear unloading response and recovery [24]. If, instead of being unloaded, the material is loaded further, there may come a point where the distributed yielding has spread through a large portion of the material causing a reduction in the activation energy spectrum for these transformation sites [24]. This leads to stress softening and localized deformation (necking) if the loading mode is uniaxial tension [24]. At very large strains, before failure, the stress may increase as deformation-induced orientation in the microstructure reduces entropy in the material [24].

\subsection{Three-element standard solid model}

A modified three-element standard solid model was used to represent the strain-rate-dependent response of PLA yarns at large deformations. The three-element standard solid model is composed by the Maxwell element in parallel with a linear spring, as shown in Fig. 1. Force in the standard solid is sum of forces in the Maxwell element and linear spring. Equation 4 governs the behaviour of the material as follows [48]:
$\frac{\eta}{E_{1}} \frac{\mathrm{d} \sigma}{\mathrm{d} t}+\sigma=\frac{\eta}{E_{1}}\left(E_{1}+E_{2}\right) \frac{\mathrm{d} \varepsilon}{\mathrm{d} t}+E_{2} \varepsilon$

where $\eta_{1} E_{1}$ and $E_{2}$ are the material parameters. $\sigma$ and $\varepsilon$ are the stress and strain, respectively. The solution of the differential Eq. (4) is given in Eq. (5) below [48]:

$$
\sigma=E_{2} \varepsilon+\eta \dot{\varepsilon}\left(1-\mathrm{e}^{\left(\frac{-E_{1} \varepsilon}{\eta \dot{\varepsilon}}\right)}\right)
$$

\section{Material and methods}

\subsection{Materials}

PLA fibres were kindly supplied by Trevira, Germany, and were used for the mechanical characterization and various degradation stages as received. PLA fibre is a texturized multifilament (167 dtex f32), composed of 32 monofilaments, each one with a diameter of $20 \mu \mathrm{m}$. The diameter of the multifilament depends on the degree of intermingling or crimping and can vary from 150 to $500 \mu \mathrm{m}$, and this variation depends on the amount of force applied to remove the intermingling or crimping. Phosphate buffer solution (PBS) with $\mathrm{pH}$ of 7.4 was used as a degradation medium for in vitro degradation of the PLA fibres.

\subsection{Methods}

\subsubsection{Degradation protocol}

PLA specimens were submerged in PBS. PLA samples were weighed and placed in 50-ml bottles. Sample-to-solution ratio of $1: 2 \mathrm{mg} / \mathrm{ml}$ was kept for every sample to ensure that all the samples were subjected to equal amount of soaking in PBS. These bottles containing PLA fibres were then subjected to a temperature of $37^{\circ} \mathrm{C}$ inside a thermal bath. PLA fibres were subjected to the degradation stages

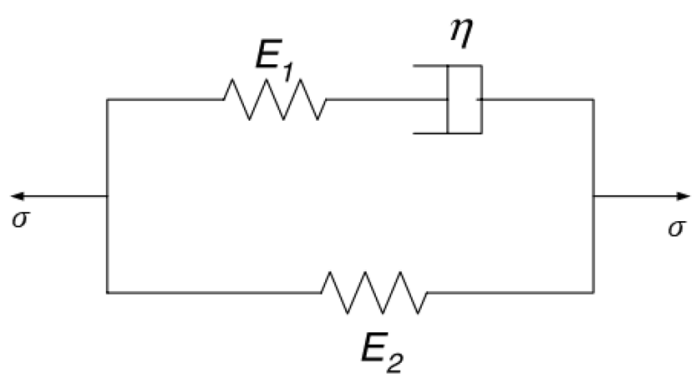

Fig. 1 Spring and dashpot representation of three-element standard solid model 
of $20,40,60,90,120$ and 150 days respectively. At the end of each degradation stage, specimens were taken out of the thermal bath and dried for $1 \mathrm{~h}$, after which they were subjected to the uniaxial tensile tests.

\subsubsection{Mechanical characterization}

Uniaxial tensile tests with five different strain rates as $10^{-4} \mathrm{~s}^{-1}, 10^{-3} \mathrm{~s}^{-1}, 50 \times 10^{-2} \mathrm{~s}^{-1}, 10^{-2} \mathrm{~s}^{-1}$ and $10^{-1} \mathrm{~s}^{-1}$ were performed under displacement control. All tensile tests were performed at room temperature up to the failure. Instron ElectoPlus E1000 machine is used to carry out these tests with a 2-kN load cell to measure the load. Gauge length for all the specimens were kept at $100 \mathrm{~mm}$. According to the experimental protocol, three samples from each group were used for measurements.

\subsubsection{Modified three-element standard solid model}

In the work done by Khan et al. [49], time- and temperature-dependent mechanical properties were explained by using a simple phenomenological viscoelastic model for polymers under finite deformations range. Khan in his paper used the standard solid model as the starting point to model the finite deformation. Figure 2 shows spring and dashpot arrangement for the model. The represented model has two modules connected in parallel: the first one is the Maxwell element which has a spring element connected in series with the dashpot element. The second module is the Kelvin element; spring in the Kelvin element has the nonlinear characteristics, which is dependent on the level of deformation. Viscosity associated with the Maxwell and Kelvin element is dependent on the strain rate as described by Khan et al. in Eq. (6) below:

$\eta=\eta_{\infty}+\frac{\eta_{0}-\eta_{\infty}}{\left(1+a \dot{\varepsilon}^{2}-\left(\frac{\dot{\varepsilon}}{10^{5}}\right)^{d}\right)^{b}}$

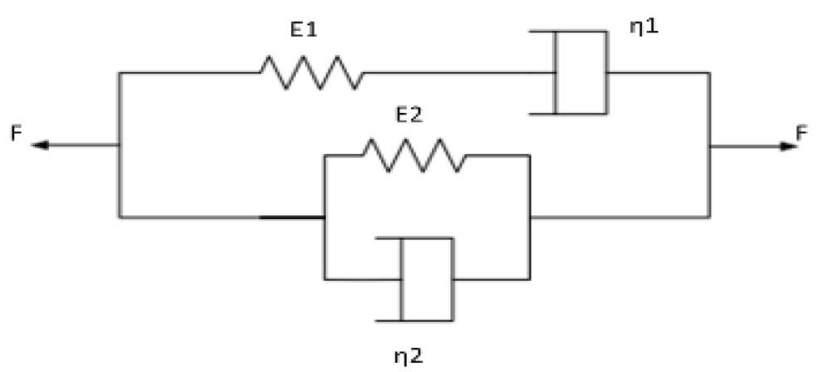

Fig. 2 Spring and dashpot representation of modified three-element standard solid model (adapted from Khan et al. [49]) where $\eta$ is the viscosity function, $\eta_{0}$ is the viscosity at the zero strain rate and $\eta_{\infty}$ is the viscosity at the infinite strain rate. $a, d$ and $b$ are material parameters, which are used to adjust the shear thinning decay at a higher strain rate. This function was originally proposed by Bird et al. [50] and has been modified ever since by other researchers depending upon the requirement of the polymeric behaviour [51-54]. A modified viscosity function with one parameter less is proposed here as in Eq. (7):

$\eta_{i}=\eta_{0}-\frac{\eta_{0}-\eta_{\infty}}{1+\left(\frac{v_{0}}{\dot{\varepsilon}}\right)^{\alpha}} \quad i=1,2$

where $\eta_{0}$ and $\eta_{\infty}$ has the usual meaning, $v_{0}$ and $a$ are used to predict the decay of shear thinning under increasing strain rate.

Material parameters were found out by using the method of least squares in Excel by using the uniaxial tensile test data. The goodness of fit was measured by using $R$-squared function of excel, which is the square of the Pearson product moment correlation coefficient. It uses Eq. (8) below to evaluate the $R$-square value; further in the text, it will be represented as $\rho^{2}$.

$\rho^{2}=\left(\frac{\sum(x-\bar{x})(y-\bar{y})}{\sqrt{\sum(x-\bar{x})^{2} \sum(y-\bar{y})^{2}}}\right)^{2}$

Here, $x$ and $y$ are sample means, the average value of $y$ 's and the average value of known $x$ 's, respectively. Experimental data are modelled by using force versus strain curve and not by stress versus strain curve. As the measurement of the area of cross section is complex for the PLA fibres. Engineering strain represented as $\varepsilon$ and is calculated as the change of length to the original length, as shown by Eq. (9):

$\varepsilon=\frac{l_{\text {final }}-l_{\text {initial }}}{l_{\text {initial }}}=\frac{\Delta l}{l_{\text {initial }}}$.

Equation 10 represents the general viscoelastic behaviour of the polymer material under finite deformation. Here $E_{1}$ and $E_{2}$ represent the stiffness of the spring, and $F$ is the force applied. $\eta_{1}$ and $\eta_{2}$ are the viscosity of dashpot element 1 and 2. $C_{1}, C_{2}$ and $n_{2}$ are the material parameters $\frac{C_{1}}{\eta_{1}} F+\dot{F}=C_{1} \dot{\varepsilon}+\frac{C_{1}}{\eta_{1}} C_{2} \varepsilon^{\left(n_{2}+1\right)}+\frac{\eta_{2}}{\eta_{1}} C_{1} \dot{\varepsilon}+C_{2}\left(n_{2}+1\right) \varepsilon^{n_{2}} \dot{\varepsilon}$

This differential equation was solved using a finite difference scheme associated with least-square method to determine the unknown parameters using the uniaxial tensile test data [49]. 


\subsubsection{Gel permeation chromatography (GPC)}

Gel permeation chromatography also known as size exclusion chromatography (SEZ) is a chromatographic method in which molecules are separated based on their size. This method is widely used for determination of polymer molecular weights [9]. Chloroform was used as an eluent for eluting PLA [55]; chloroform was forced through the column at a rate of $1 \mathrm{ml} / \mathrm{min}$. PLA sample was then dissolved in the chloroform and was introduced in the eluent stream running through the column; $15 \mathrm{mg}$ of PLA and $3 \mathrm{ml}$ of chloroform were used for this purpose. Temperature of $30^{\circ} \mathrm{C}$ was maintained during the single run, and molecular weight distribution of the polymer was obtained in terms of three scalar quantities such as number average molecular weight $\left(M_{n}\right)$, weight average molecular weight $\left(M_{w}\right)$ and $Z$-averaged molecular weight $\left(M_{z}\right)$. Ratio of weighted average to the number average molecular weight is called the polydispersity index.

\subsubsection{Differential scanning calorimetry (DSC)}

DSC is a characterization technique, which is used for analysing thermal transitions. DSC enables the determination of glass transition temperature $T_{\mathrm{g}}$ crystallization temperature $\left(T_{\mathrm{c}}\right)$ and melting temperatures $\left(T_{\mathrm{g}}\right)$, and the corresponding enthalpy and entropy change show either change in heat capacity or a latent heat [9-12]. DSC measurements were performed in a DSC 214 Polyma (NETZSCH), with the weight of the sample taken in between 3 and $10 \mathrm{mg}$, depending upon the density of the sample. Material was heated to $250^{\circ} \mathrm{C}$ at a heating rate of $10^{\circ} \mathrm{C} / \mathrm{min}$, then cooled down to $10^{\circ} \mathrm{C}$ at a cooling rate of $10^{\circ} \mathrm{C} / \mathrm{min}$ and then reheated to $250^{\circ} \mathrm{C}$. Nitrogen atmosphere is used to maintain the inert atmosphere, and a small sample size was preferred to avoid the temperature gradient inside the sample. Degree of crystallinity of the sample was calculated as in Eq. (11).

Degree of crystallinity $=\left(\frac{(\Delta H)_{\text {melt }}}{(\Delta H)_{100 \% \text { crystalline sample }}}\right) \times 100$,

where

$(\Delta H)_{\text {melt }}$ is enthalpy of melting,

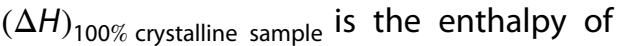
melt of a fully crystallized sample,

The term $(\Delta H)_{100 \%}$ crystalline sample is a reference value and represents the heat of melting of the $100 \%$ crystalline polymer. Enthalpy of melt of $100 \%$ crystalline PLA sample is $93 \mathrm{~J} / \mathrm{g}[56,57]$.

\section{Results and discussion}

\subsection{Gel permeation chromatography (GPC)}

Table 2 shows the PLA molecular weight result obtained for undegraded and 90-day-degraded PLA fibres. Idea was to show the evolution of molecular weight and compare it with the previous studies, as this is already well established on numerous occasions such as Weir et al. and Vieira et al. These results can be explained by the exponential law as mentioned in Eq. (1).

\subsection{DSC analysis versus time}

PLA is a semi-crystalline polymer consisting of both amorphous and crystalline regions. During degradation, amorphous region degrades first which results in an increase in fibre crystallinity [21]. Figure 3 shows DSC results of undegraded and degraded PLA fibres.

Polymers can exist in a glassy or in a rubbery state; at a temperature below $T_{\mathrm{g}}$, they exist in a glassy state, as chains are more rigid and cannot move freely. Above $T_{\mathrm{g}}$, polymer exists in a rubbery phase, as the amorphous structure becomes mobile above $T_{\mathrm{g}}$ [9]. At this point, the mechanical properties of the polymer change from those of a brittle material to those of an elastic material. The polymer chains have high mobility above $T_{\mathrm{g}}$, and this transition occurs over a range of temperature; onset temperature is taken as a glass transition temperature. From Table $3, T_{g}$ for PLA remains in the range of $53-57^{\circ} \mathrm{C}$ and change is seen for 150-day-degraded sample.

Figure 3 shows PLA samples at different stages and the region where PLA is melting. The temperature at the peak represents the melting temperature of the polymer, represented as $T_{m}$, and these values are mentioned in Table 3 . The area of the peak for this region will give the latent heat of melting. At the $T_{m}$, the polymer chains move freely and thus do not have ordered arrangements. Melting is an

Table 2 Molecular weight evolution for 90-day-degraded PLA fibres obtained from GPC

\begin{tabular}{llll}
\hline $\begin{array}{l}\text { Degradation time } \\
\text { (days) }\end{array}$ & $\begin{array}{l}M_{\mathrm{n}} \\
(\mathrm{g} / \mathrm{mol})\end{array}$ & $M_{\mathrm{w}}$ & $M_{\mathrm{z}}$ \\
\hline 0 & 13,663 & 54,699 & 126,508 \\
90 & 7941 & 36,323 & 86,209 \\
$\begin{array}{l}\text { Degradation rate } \mu \\
(1 / \text { day) }\end{array}$ & 0.0060 & 0.0045 & 0.0043 \\
\hline
\end{tabular}




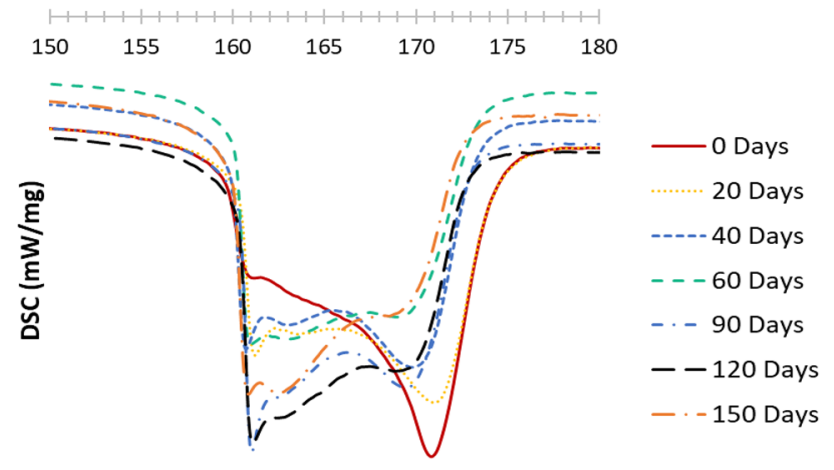

Temperature $\left({ }^{\circ} \mathrm{C}\right)$

Fig. 3 DSC results of PLA fibres with the increase in degradation stages

Table $3 T_{\mathrm{g}}, T_{\mathrm{m}}$ and \% crystallinity values of PLA fibres with the increase in degradation

\begin{tabular}{llll}
\hline No. of days & $\begin{array}{l}T_{\mathrm{g}} \text { (onset } \\
\text { temp) }{ }^{\circ} \mathrm{C}\end{array}$ & $\begin{array}{l}T_{\mathrm{m}} \text { (peak tem- } \\
\text { perature) }{ }^{\circ} \mathrm{C}\end{array}$ & $\%$ Crystallinity \\
\hline 0 & 54.9 & 170.8 & 60.7 \\
20 & 56.8 & 171.0 & 61.6 \\
40 & 55.0 & 169.8 & 60.5 \\
60 & 53.6 & 161.0 & 62.1 \\
90 & 55.5 & 161.0 & 62.7 \\
120 & 54.5 & 161.1 & 62.3 \\
150 & 48.1 & 160.8 & 60.7 \\
\hline
\end{tabular}

endothermic process, which requires absorption of heat. During melting, at least two peaks are observed for all PLA samples, which indicates the presence of at least two distinct crystal lamellae or the existence of different crystal structures $[58,59]$. The crystals are of varied size and forms, and the amorphous phase near the crystallite interface is constrained and less mobile than the amorphous chains far from the crystallite boundaries, which may be the reason two peaks were seen, and this phenomenon was first mentioned by Bassett et al. [60] and Cebe et al. [61]. They state that distinct crystal lamellae of different thickness are formed during the DSC experiment. Supaphol et al. [62] explained that low-temperature endotherm is due to the melting of the lamellae which is thinner, and the higher temperature endotherm is due to the melting of thicker lamellae.

In Table 3, it is observed that \% crystallinity of PLA samples does not vary significantly and remains between 60 and $63 \%$, indicating the structure of PLA remains intact with no decay of crystalline region during 150 days. Table 3 shows the $T_{\mathrm{g}}$ and $T_{\mathrm{m}}$ evolution during degradation time. The glass transition temperature, $T_{g^{\prime}}$, showed insignificant variation $\left(53-57^{\circ} \mathrm{C}\right)$ till 120 days of degradation with a further small drop for the last stage of degradation, which seems insignificant. The melting temperature, $T_{m}$, remains constant from undegraded till 40 days of degradation and then takes a small dip after which remains constant till 150 days degradation.

\subsection{Mechanical properties versus time}

PLA fibres were subjected to uniaxial tensile tests after degradation stages of $0,20,40,60,90,120$ and 150 days. To avoid the redundancy, load versus displacement graphs from undegraded PLA fibres and 150-day-degraded PLA fibres are shown in the main text, and data from rest of the degradation stages are included as supplementary material. Figure 4 shows uniaxial tensile test results of undegraded PLA fibres tested at room temperature at different strain rates. Force required to reach inflection point increases with increase in strain rate, as at higher strain rate the molecular mobility of the polymer chains decreases, thereby making the chains stiffer which require more force to reach the inflection point [56-59, 63-67].

Figure 5 shows uniaxial tensile test results of PLA fibres after 150 days of degradation. Force required to reach inflection point increases with increase in strain rate. At higher strain rate, molecular mobility of the polymer chains decreases, thereby making the chains stiffer which require more force to reach the inflection point [56-59, 63-67]. Load versus displacement graph of Figs. 4 and 5 has two regions: one before inflection point (elastic region) and another after inflection point. Elastic region is small as compared to the second region; initial stiffness is calculated from the slope of the linear portion of elastic region, while secondary stiffness is calculated from linear portion of the second region. The point which separates elastic region from the second region is called yield point. Inset figure in Figs. 4 and 5 shows the elastic region for both degradation stages; from figures it is clear that elastic region for 150-day-degraded PLA fibres is almost double than that of the undegraded PLA fibres.

Upon application of load on PLA multifilament, friction starts acting between the filaments. When these fibres are soaked in PBS, they absorb water molecules and become soft. Thus, water acts as a lubricant allowing PLA fibres to reach higher load levels, provided degradation is not severe. Hydrophobic nature of PLA explains the low rate of degradation [68], as not enough water molecules are able to get inside the molecular structure, which justifies their low degradation behaviour. From experimental results, it is concluded after 150 days of degradation, PLA fibres were capable of withstanding significant amount of mechanical loading on comparison with pristine fibres. 


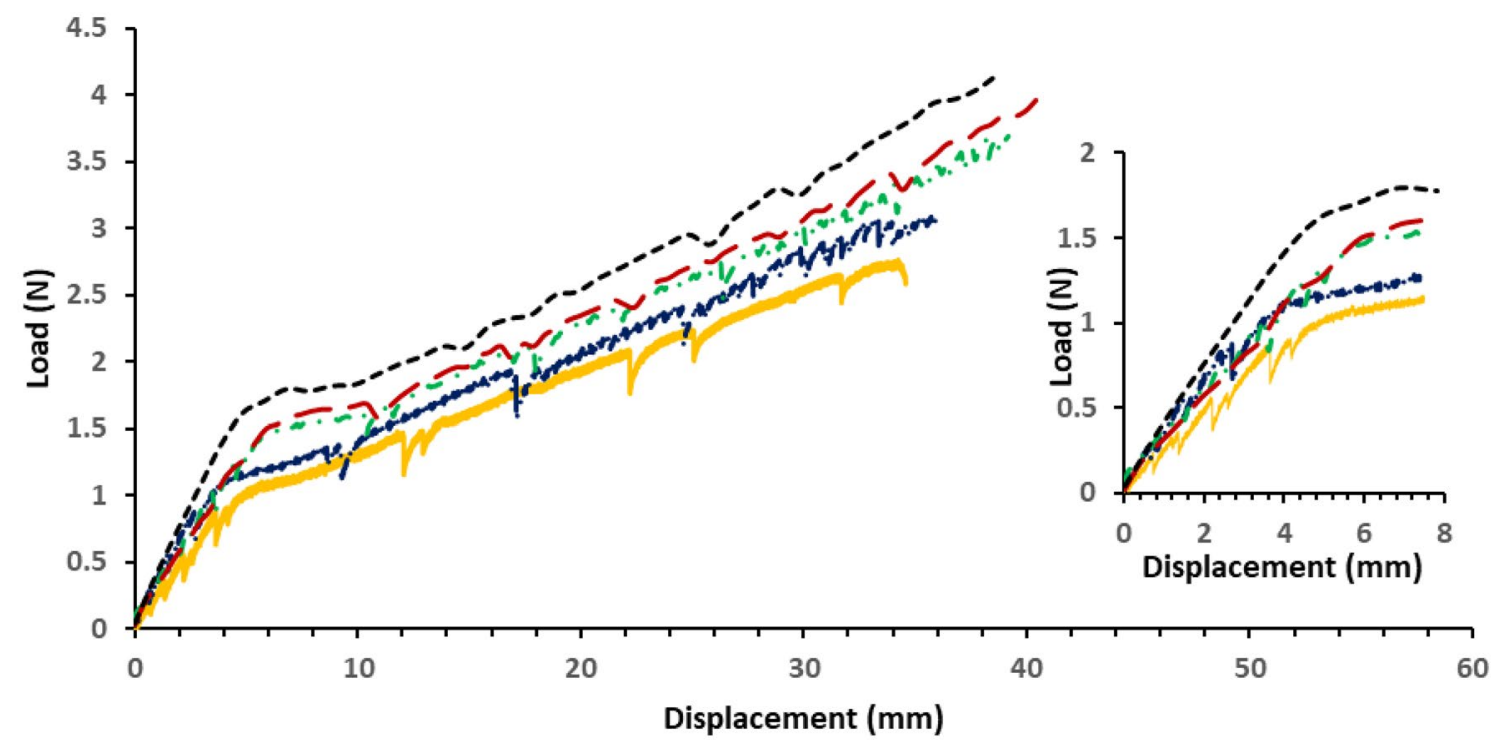

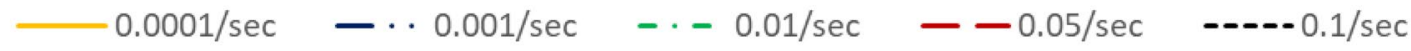

Fig. 4 Load versus displacement curve for undegraded PLA fibres at different strain rates

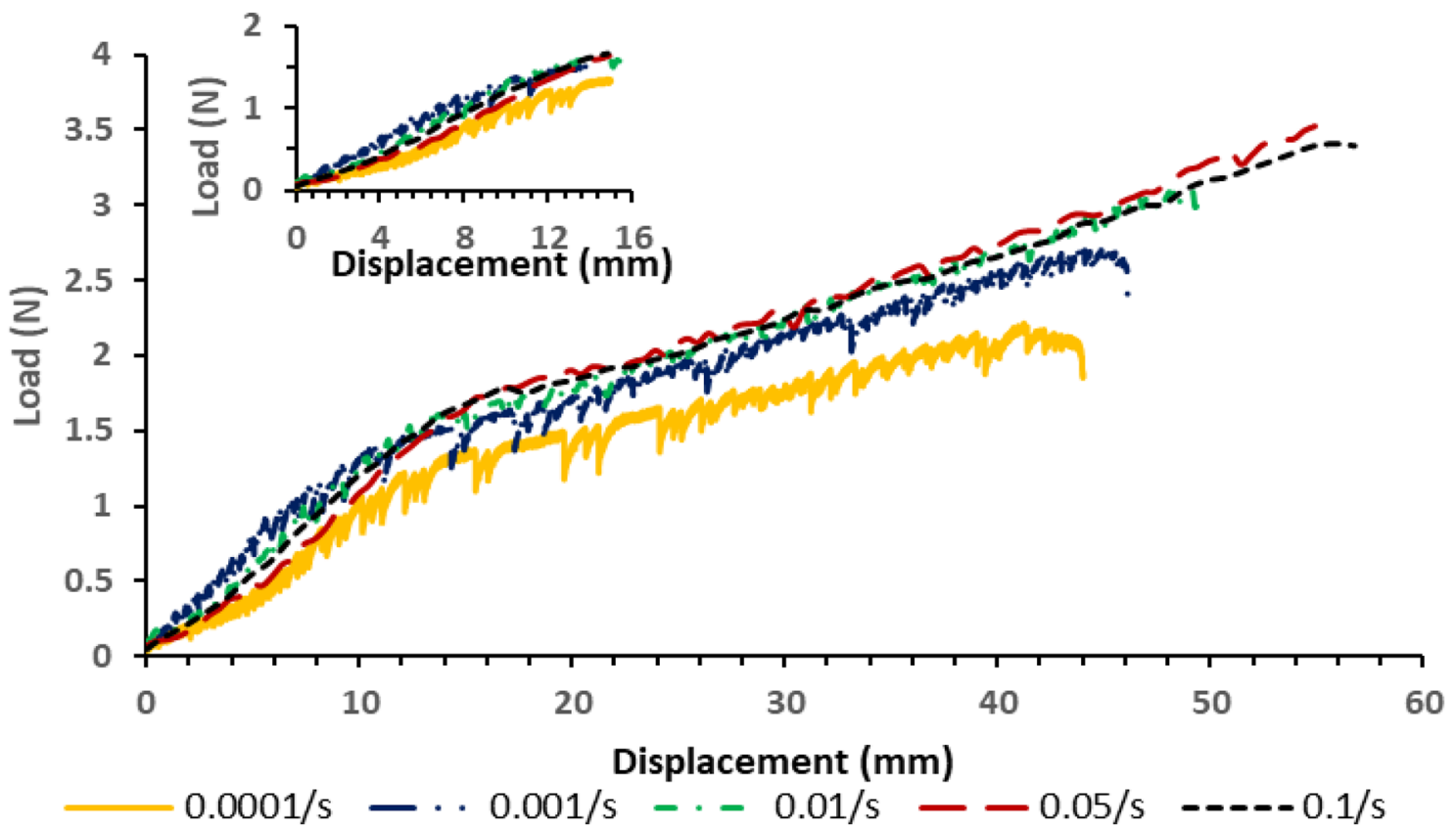

Fig. 5 Load versus displacement curve for 150-day-degraded specimens at different strain rates

Further, as PBS get swelled inside PLA structure, which makes polymer soft with degradation stages (progressively increasing), failure now occurs at large deformation. Ester group is responsible for the degradation leading to chain scission. When ester bond in polymer chain is attacked by the water molecule, it degrades into the shorter chain containing the carboxylic end group.
As the number of chains containing carboxylic group increases with time, they start to act as a catalyst and catalyse the hydrolysis of other ester bonds $[69,70]$.

Averett et al. [71] described the linear-elastic and linear strain-hardening response of the nylon 66 fibres as piecewise stress-strain $(F-d)$ equation that governs this response and described as in Eq. (12): 
Table 4 Values of different mechanical parameters at a strain rate of $0.0001 / \mathrm{s}$ and $0.1 / \mathrm{s}$ along with standard deviation for the undegraded PLA fibres

\begin{tabular}{lllllll}
\hline Strain rate $(1 / \mathrm{s})$ & $\begin{array}{l}\text { Max. displacement } \\
(\mathrm{mm})\end{array}$ & Max. load $(\mathrm{N})$ & Initial stiffness $(\mathrm{N} / \mathrm{mm})$ & $\begin{array}{l}\text { Force at inflection (N) } \\
\text { Displacement }\end{array}$ & $\begin{array}{l}\text { Secondary } \\
\text { at inflection } \\
(\mathrm{mm})\end{array}$ & $\begin{array}{l}\text { stiffness }(\mathrm{N} / \\
\mathrm{mm})\end{array}$ \\
\hline 0.0001 & $34.5729 \pm 1.5353$ & $2.6086 \pm 0.1249$ & $0.2212 \pm 0.0296$ & $0.8396 \pm 0.0571$ & $3.9875 \pm 0.5459$ & $0.0605 \pm 0.0029$ \\
0.1 & $38.8031 \pm 1.2409$ & $4.1689 \pm 0.2660$ & $0.3656 \pm 0.0092$ & $1.6137 \pm 0.1414$ & $4.8344 \pm 0.0014$ & $0.0756 \pm 0.0016$ \\
\hline
\end{tabular}

$F= \begin{cases}E \cdot d & d<\frac{F_{y}}{E} \\ F_{\mathrm{y}}+H\left(d-\frac{F_{y}}{E}\right) & d \geq \frac{F_{y}}{E}\end{cases}$

where $E$ is the stiffness of the PLA fibres and $H$ is the secondary stiffness and $F_{y}$ is the force at yield. The strength of the PLA material is defined as in Eq. (13):

$F_{\max }=F_{y}+H\left(d_{\max }-\frac{F_{y}}{E}\right)$

where $F_{\max }$ is force at break and $d_{\max }$ is maximum displacement. Equations (12) and (13) are used to define force versus displacement for undegraded PLA fibres at a strain rate of $0.0001 / \mathrm{s}$ and $0.1 / \mathrm{s}$. Table 4 shows the values of different mechanical parameters along with the standard deviation.

Figure 6 shows the tenacity versus displacement curve of the undegraded PLA fibres at a strain rate of $0.0001 / \mathrm{s}$ and $0.1 / \mathrm{s}$. Tenacity is defined as how much force a fibre can hold per linear density; breaking tenacity is the force divided by the linear density of the unstrained material. These results are compared with data obtained by Farrington et al. [72] and Hossain et al. [73] for PLA fibres. From Fig. 6, tensile results from Farrington et al. are in between to that obtained at a strain rate of $0.0001 / \mathrm{s}$ and $0.1 / \mathrm{s}$ respectively. Hossain et al. shows weakening of fibres after inflection point. Table 5 shows the comparison of these PLA fibres in terms of breaking tenacity and inflection tenacity. These results show that PLA fibres used in this study have a similar behaviour to those used by the Farrington et al. [72]. For Hossain et al. [73], PLA fibres show similarity until the inflection point and have the lowest breaking tenacity of all.

\subsection{Effect of strain rate and degradation on mechanical parameters}

The force at break is the maximum force attained by the fibres at a time of failure. Force at break of PLA fibres increases with strain rate, as secondary stiffness is increasing with strain rate, and therefore, the force required to reach higher values shows a continuous increase because of which more force is required to break the fibres at

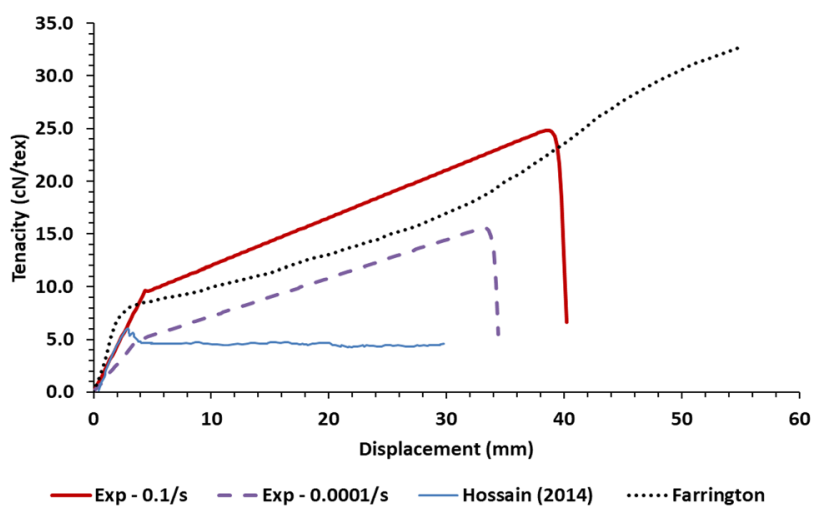

Fig. 6 Tenacity displacement curve of the PLA fibres at a strain rate of $0.0001 / \mathrm{s}$ and $0.1 / \mathrm{s}$, and their comparison with the Farrington et al. [72] and Hossain et al. [73]

Table 5 Tensile properties of different PLA fibres

\begin{tabular}{lll}
\hline PLA data & $\begin{array}{l}\text { Tenacity at inflection } \\
\text { (cN/tex) }\end{array}$ & $\begin{array}{l}\text { Breaking } \\
\text { tenacity (cN/ } \\
\text { tex) }\end{array}$ \\
\hline Farrington et al & 8.61 & 32.71 \\
Hossain et al & 6.05 & 4.57 \\
PLA-0.0001/s & 5.24 & 15.32 \\
PLA-0.1/s & 9.55 & 24.26 \\
\hline
\end{tabular}

higher strain rate. Figure 7 shows the percentage increase and decrease in various mechanical properties from undegraded PLA fibres and 150-day-degraded PLA fibres. Maximum elongation and the inflection point show increase in the value in comparison with undegraded PLA fibres. These two properties show increase as the PLA fibres get soft after getting exposed to degradation. Initial stiffness, secondary stiffness and force at break decrease because of the same reason as fibres get soft after getting exposed to PBS. However, rate of degradation in PLA fibres is slow as severe degradation is not noticed.

Figure 8 shows force at break versus degradation time and Fig. 9 shows stiffness evolution with degradation. Tables 6 and 7 show corresponding values of the exponential law along with their coefficient of determination. Following the same approach from Eq. (1), exponential 
Fig. 7 Percentage increase/ decrease in different mechanical parameters from undegraded PLA to 150-daydegraded PLA fibres at different strain rates
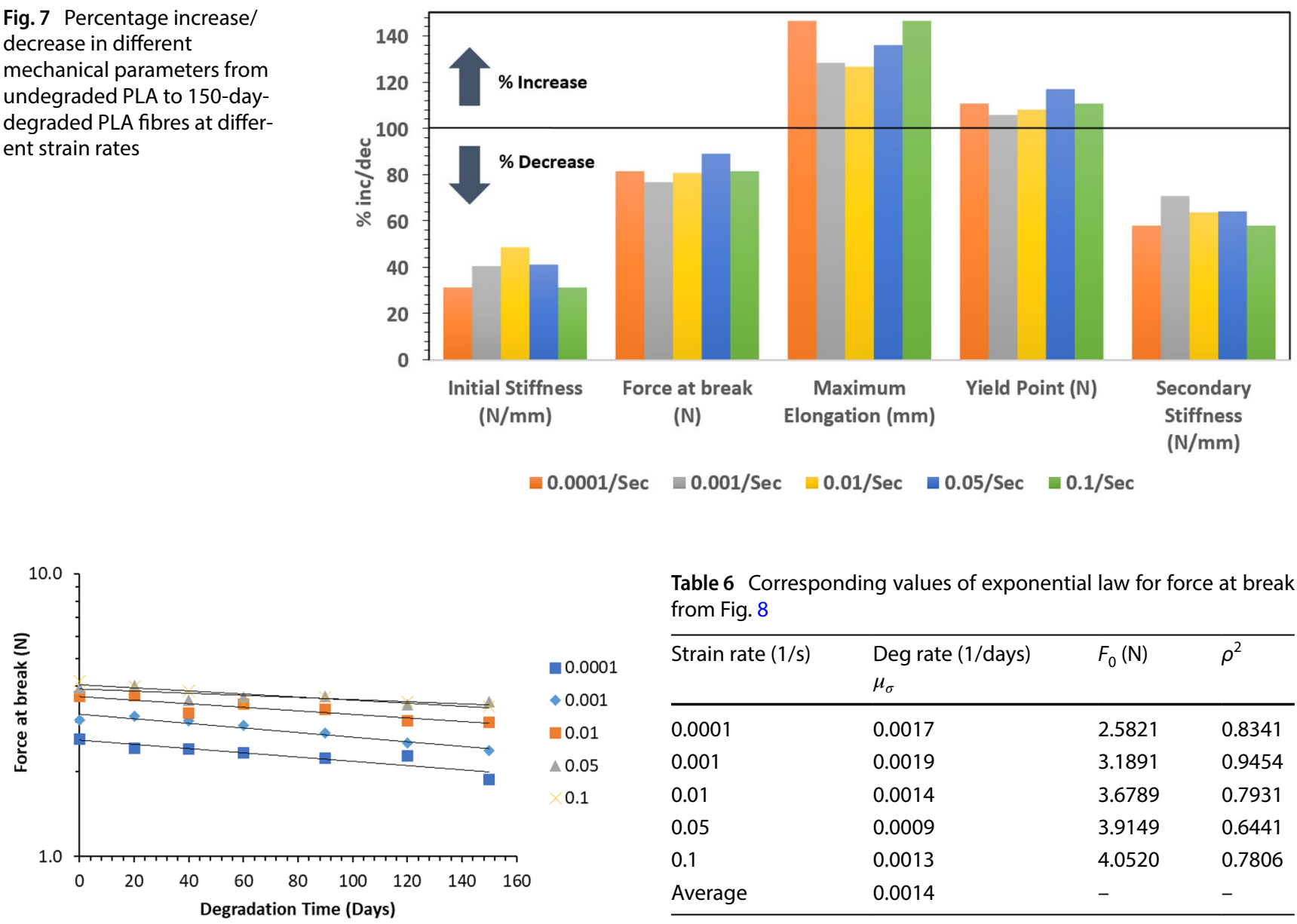

Table 6 Corresponding values of exponential law for force at break from Fig. 8

\begin{tabular}{|c|c|c|c|}
\hline Strain rate $(1 / \mathrm{s})$ & $\begin{array}{l}\text { Deg rate (1/days) } \\
\mu_{\sigma}\end{array}$ & $F_{0}(\mathrm{~N})$ & $\rho^{2}$ \\
\hline 0.0001 & 0.0017 & 2.5821 & 0.8341 \\
\hline 0.001 & 0.0019 & 3.1891 & 0.9454 \\
\hline 0.01 & 0.0014 & 3.6789 & 0.7931 \\
\hline 0.05 & 0.0009 & 3.9149 & 0.6441 \\
\hline 0.1 & 0.0013 & 4.0520 & 0.7806 \\
\hline Average & 0.0014 & - & - \\
\hline
\end{tabular}

Fig. 8 Force at break evolution with days of degradation

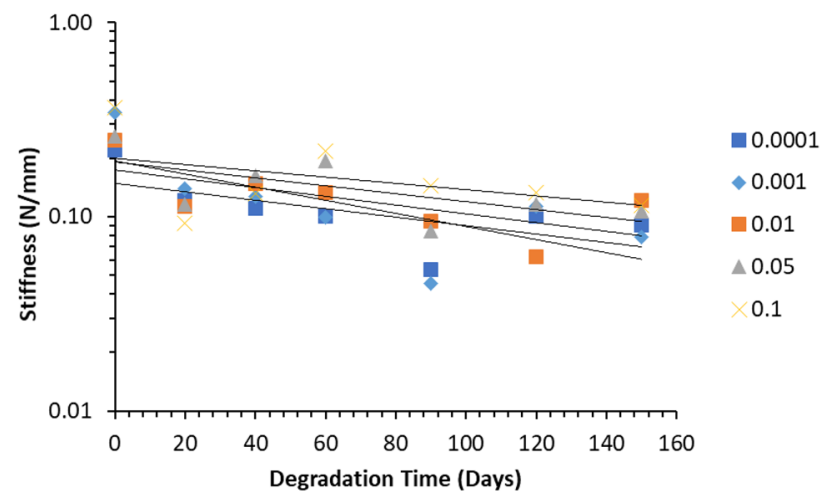

Fig. 9 Stiffness evolution with days of degradation

law reasonably predicts the force at break and stiffness values for PLA fibres versus degradation. Weir et al. [30] and Vieira et al. [31] showed similar evolution of strength with degradation time.

\subsection{Constitutive modelling of PLA fibres}

The modified three-element standard solid model was extended to include the effect of progressive degradation of the PLA fibres. Experimental data are modelled by using force versus strain curve and not by stress versus strain curve because of the complexity in measuring cross-sectional area of PLA fibres. At each stage of degradation, it was assumed that stiffness parameters $\left(c_{1}\right.$ and $c_{2}$ ) remain constant and viscous parameters $\left(\eta_{1}\right.$ and $\eta_{2}$ ) are strain rate dependent. Thus, stiffness parameters are assumed to change with degradation and viscous parameters are assumed to be unaffected by degradation.

\subsubsection{Undegraded PLA fibres}

Material parameters were obtained from uniaxial tensile test data, and Table 8 shows the value of parameters obtained by fitting the experimental data, while keeping the above-mentioned assumptions. Model was able to 
Table 7 Corresponding values of exponential law for stiffness from Fig. 10

\begin{tabular}{|c|c|c|c|}
\hline Strain rate $(1 / \mathrm{s})$ & $\begin{array}{l}\text { Deg rate (1/days) } \\
\mu_{E}\end{array}$ & $E_{0}\left(\mathrm{~N} / \mathrm{mm}^{2}\right)$ & $\rho^{2}$ \\
\hline 0.0001 & 0.0050 & 0.1486 & 0.4158 \\
\hline 0.001 & 0.0078 & 0.1938 & 0.4719 \\
\hline 0.01 & 0.0052 & 0.1740 & 0.4457 \\
\hline 0.05 & 0.0047 & 0.1912 & 0.4270 \\
\hline 0.1 & 0.0037 & 0.1999 & 0.1932 \\
\hline Average & 0.0053 & - & - \\
\hline
\end{tabular}

Table 8 Material parameters of modified three-element standard solid model for undegraded PLA

\begin{tabular}{llllll}
\hline $\begin{array}{l}\text { Strain rate } \\
\text { parameters }\end{array}$ & $0.0001 / \mathrm{s}$ & $0.001 / \mathrm{s}$ & $0.01 / \mathrm{s}$ & $0.05 / \mathrm{s}$ & $0.1 / \mathrm{s}$ \\
\hline$c_{1}(\mathrm{~N} / \mathrm{m})$ & 21.6 & 21.6 & 21.6 & 21.6 & 21.6 \\
$c_{2}(\mathrm{~N} / \mathrm{m})$ & 13.7 & 13.7 & 13.7 & 13.7 & 13.7 \\
$n_{2}$ & 1 & 1 & 1 & 1 & 1 \\
$\eta_{1}(\mathrm{~N} / \mathrm{m} \mathrm{s})$ & 10,762 & 845 & 115.4 & 25.1 & 12.2 \\
$\eta_{2}(\mathrm{~N} / \mathrm{m} \mathrm{s})$ & 3202 & 660 & 54.9 & 13.2 & 9.1 \\
\hline
\end{tabular}

fit the experimental data as shown in Fig. 10 with a high coefficient of determination $\left(\rho^{2}\right)$. Viscous parameters were decreasing with increase in strain rate, because of expected shear thinning from polymeric materials. Shear thinning indicates that with an increase in strain rate, viscous flow experienced by polymer molecules is decreasing $[48,49,74]$, and Fig. 11 shows these results.

\subsubsection{Viscosity function}

Table 9 shows values of parameters obtained for the viscosity function. $\eta_{0}$ and $\eta_{\infty}$ represents value of viscosity at zero strain rate and infinite strain rate, respectively, for dashpot 1 and dashpot 2 . Figure 12 shows modelling result of viscous parameters from Eq. (7), which depicts the shear-thinning phenomena quite well. $\rho^{2}$ values from Fig. 12 shows that Eq. (7) is suitable for predicting the viscosity values at different strain rates. Following this, viscous parameters were kept constant for degradation stages and are varied only for different strain rates.

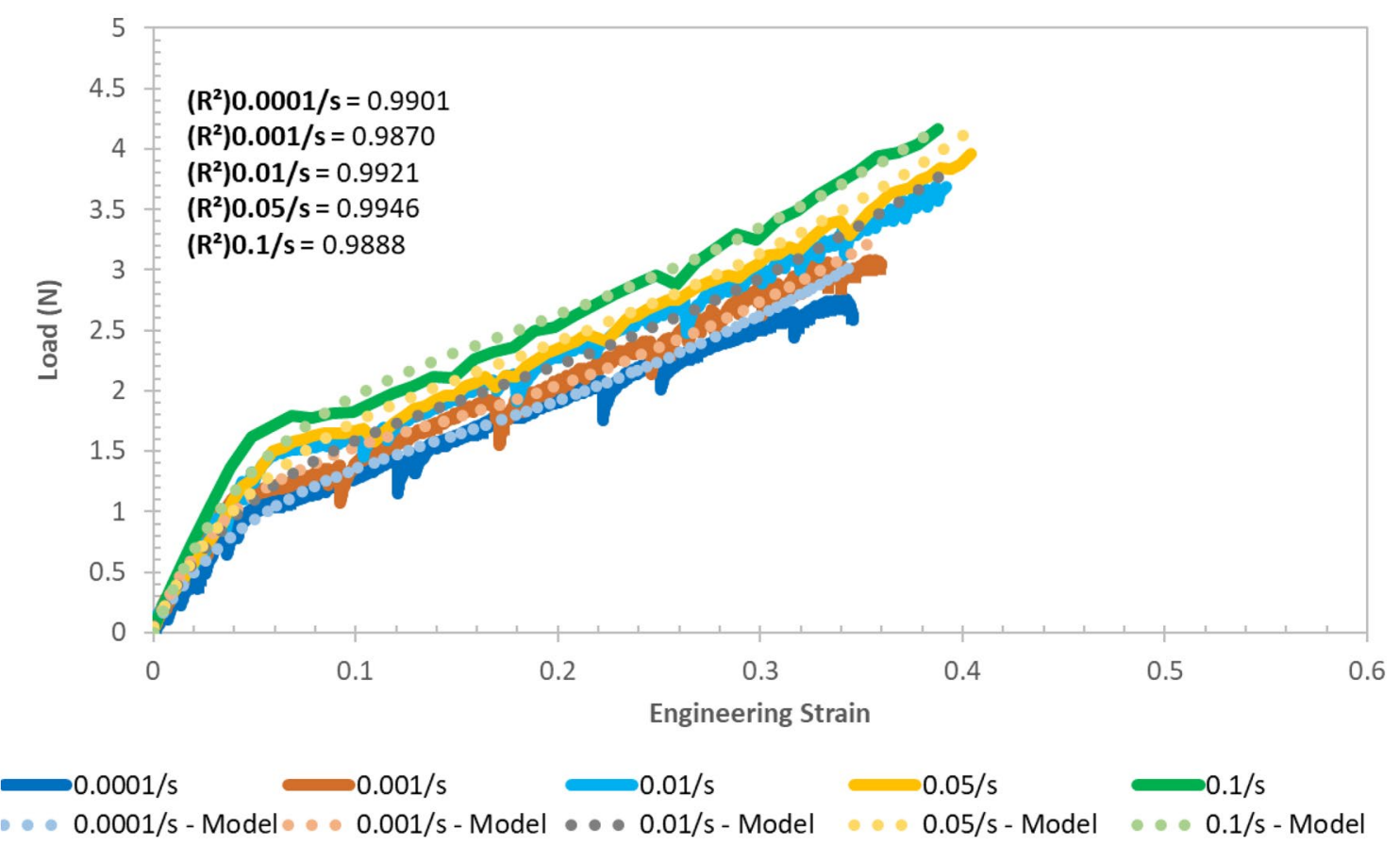

Fig. 10 Modelling the constant strain rate (CSR) behaviour of undegraded PLA fibres by modified three-element standard solid model 


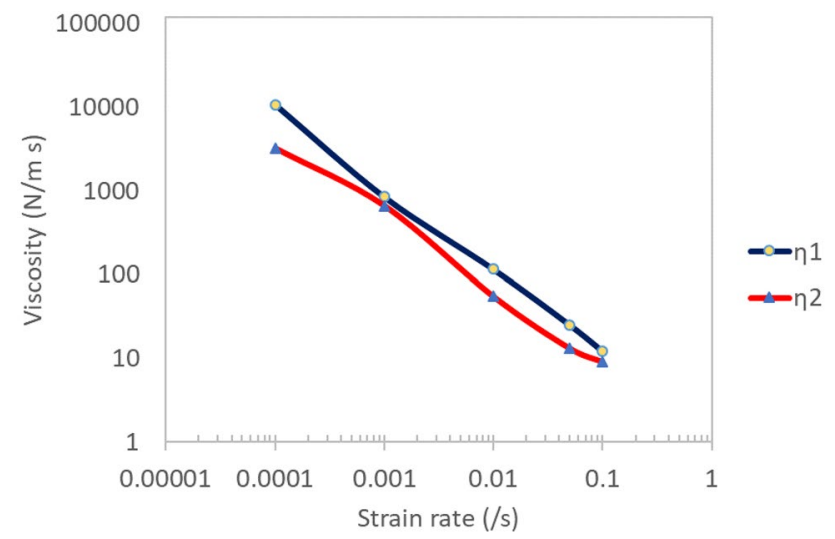

Fig. 11 Evolution of viscous parameter of PLA fibres

Table 9 Material parameters that are used to calculate the viscosity function

\begin{tabular}{lll}
\hline Parameters & Viscous dashpot 1 & Viscous dashpot 2 \\
\hline$\eta_{0}(\mathrm{~N} / \mathrm{m} \mathrm{s})$ & $1,086,732$ & 8625.22 \\
$\eta_{\infty}(\mathrm{N} / \mathrm{m} \mathrm{s})$ & 2.3 & 2.3 \\
$v_{0}(1 / \mathrm{s})$ & 0.000001 & 0.000059 \\
$a$ & 1 & 1 \\
\hline
\end{tabular}

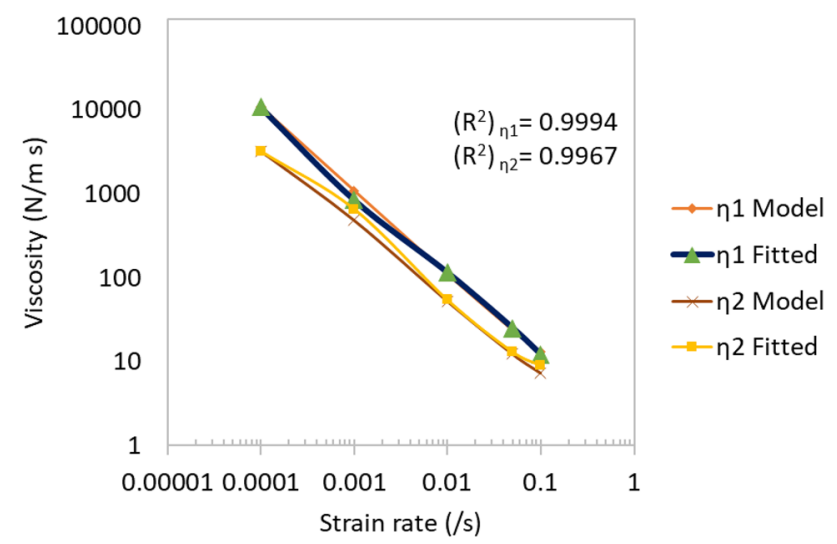

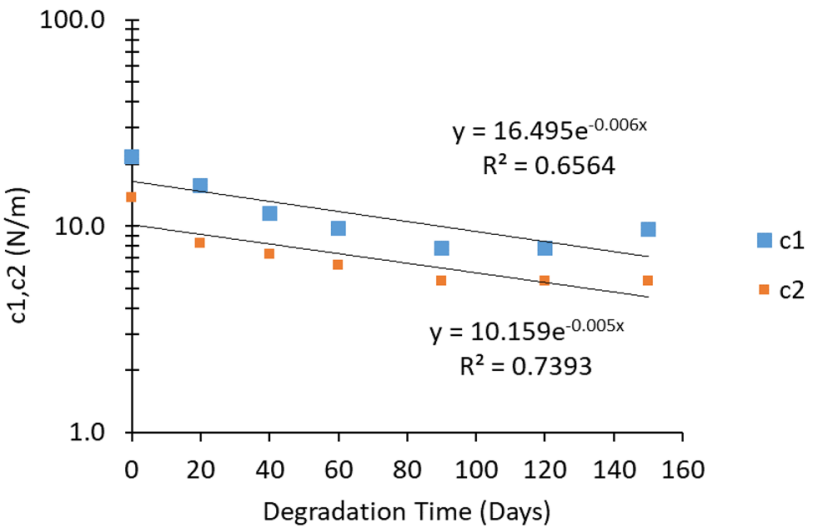

Fig. 13 Evolution of modified three-element standard solid model parameters with the degradation

\subsubsection{Stiffness function}

Table 10 shows that with increase in degradation, stiffness parameters $C_{1}$ and $C_{2}$ decreases with degradation; $n_{2}$ is constant with respect to stages of degradation and does not vary with strain rate or with degradation. Following the discussion in Sect. 2, incorporation of damage law in the constitutive model completes the modelling representation of the experimental data. In this case, an exponential law represents the stiffness parameters as a function of degradation days, as shown in Fig. 13. The degradation decay of these coefficients is quite similar to decay of initial stiffness, represented in Table 7.

Figures 14, 15, 16, 17 and 18 show modelling of constant strain rate (CSR) behaviour for various degradation stages. From these figures, the model fits the experimental results well as shown by the $R$-squared value. There are some deviations at the end of the curves, especially at higher strain rates, i.e. the model predicts a slight stiffer behaviour to near the failure region.

Fig. 12 Modelling the viscous parameter of PLA fibres by Eq. (7)

Table 10 Evolution of stiffness parameters of modified threeelement standard solid model with degradation

\begin{tabular}{llllllll}
\hline $\begin{array}{l}\text { Stiffness } \\
\text { parameters }\end{array}$ & \multicolumn{6}{l}{ Number of days } \\
\cline { 2 - 7 } & 0 days & 20 days & 40 days & 60 days & 90 days & 120 days & 150 days \\
\hline$c_{1}(\mathrm{~N} / \mathrm{m})$ & 21.6 & 15.7 & 11.5 & 9.8 & 7.8 & 7.8 & 9.7 \\
$c_{2}(\mathrm{~N} / \mathrm{m})$ & 13.7 & 8.3 & 7.3 & 6.5 & 5.4 & 5.4 & 5.4 \\
\hline
\end{tabular}




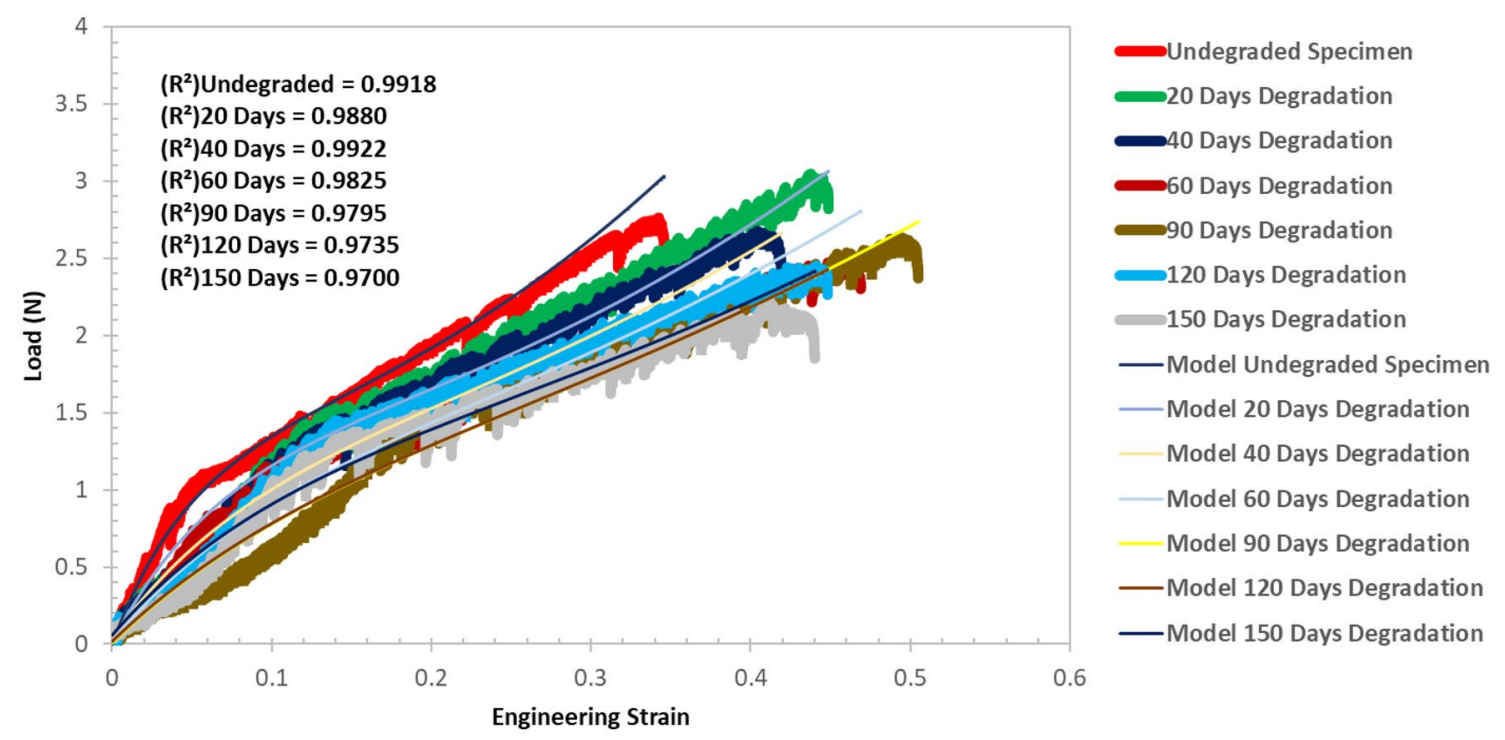

Fig. 14 Modelling the degradation behaviour of PLA fibres at a constant strain rate of $0.0001 / \mathrm{s}$ by modified three-element standard solid model

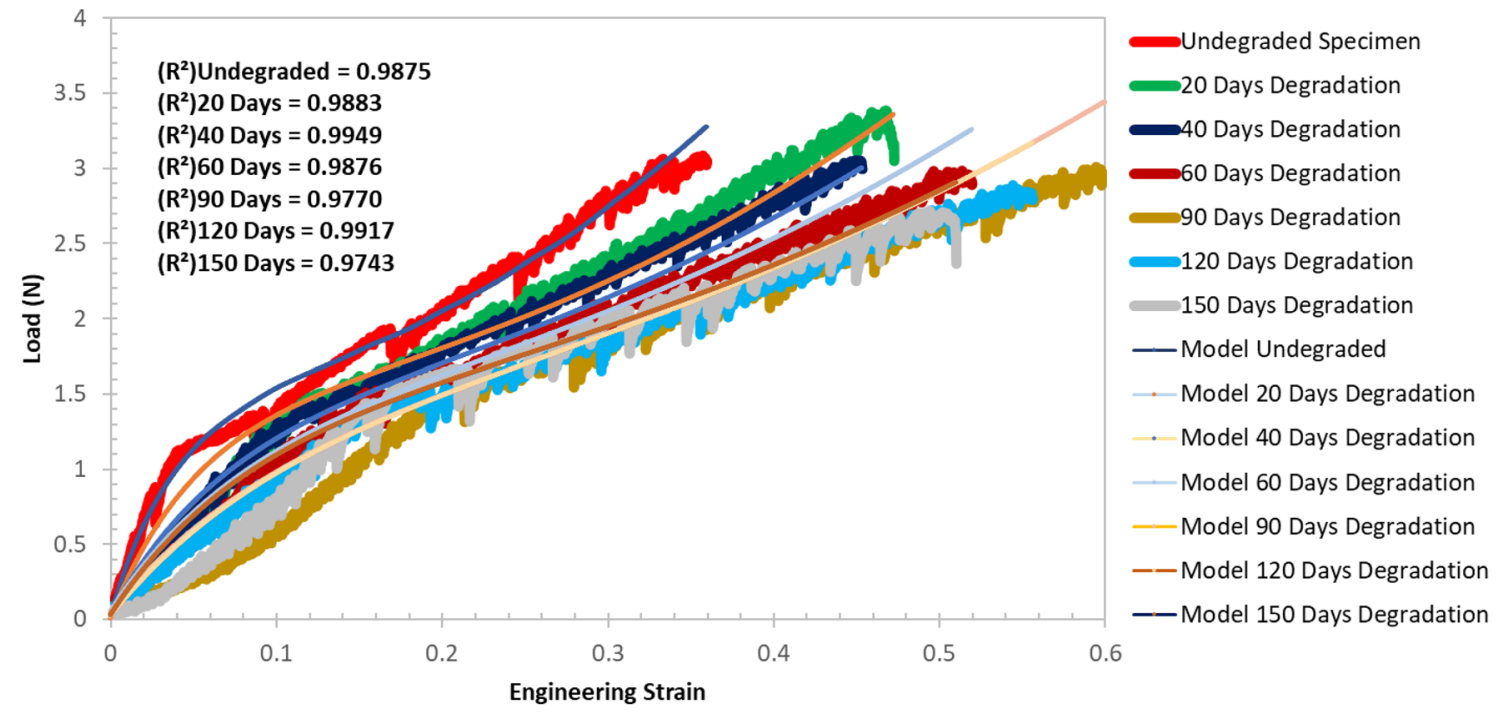

Fig. 15 Modelling the degradation behaviour of PLA fibres at a constant strain rate of $0.001 / \mathrm{s}$ by modified three-element standard solid model 


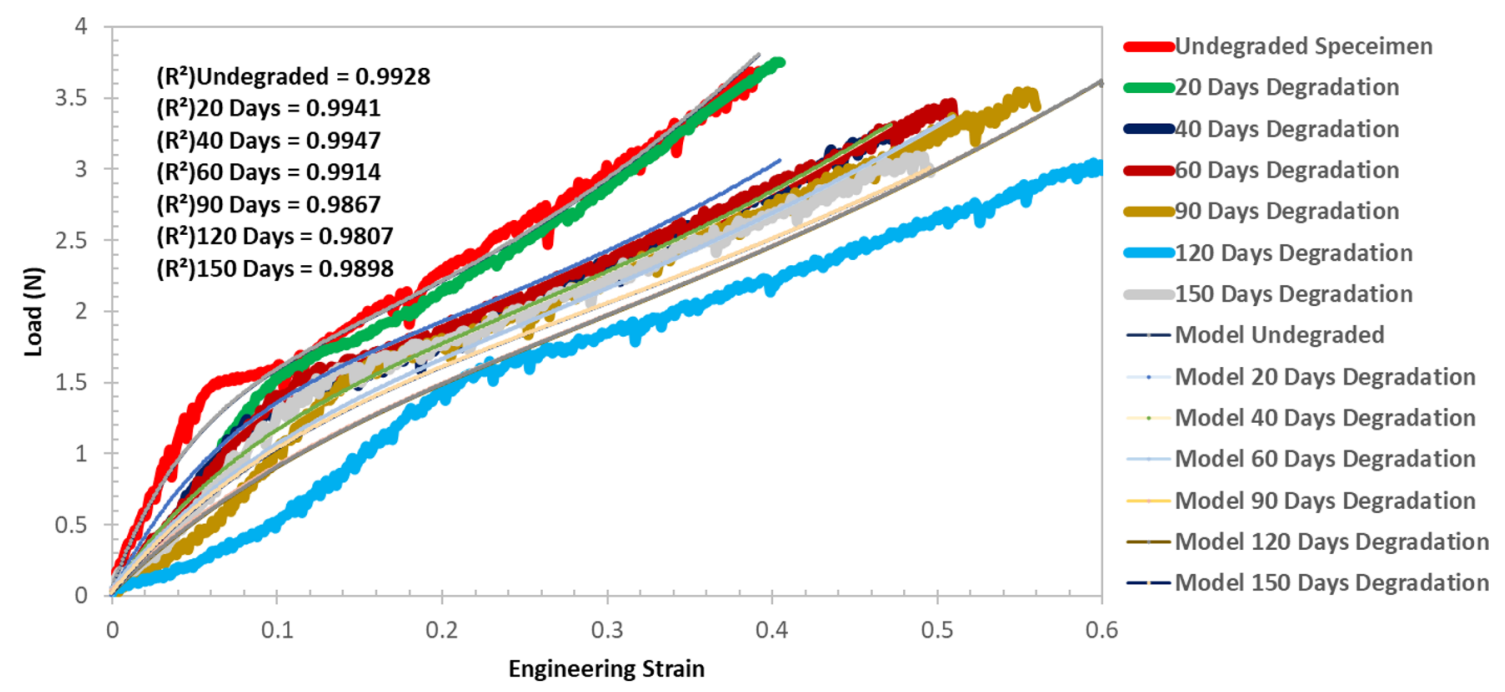

Fig. 16 Modelling the degradation behaviour of PLA fibres at a constant strain rate of $0.01 / \mathrm{s}$ by modified three-element standard solid model

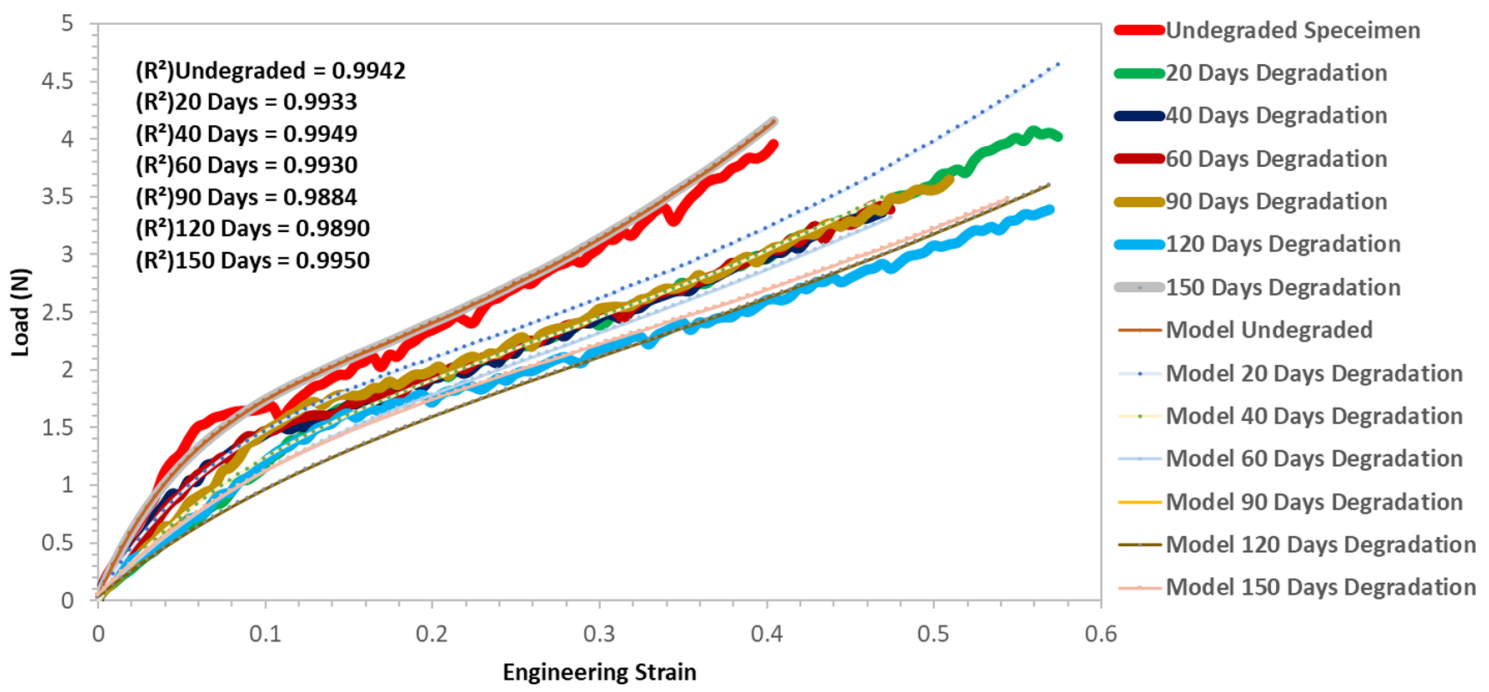

Fig. 17 Modelling the degradation behaviour of PLA fibres at a constant strain rate of $0.05 / \mathrm{s}$ by modified three-element standard solid model 


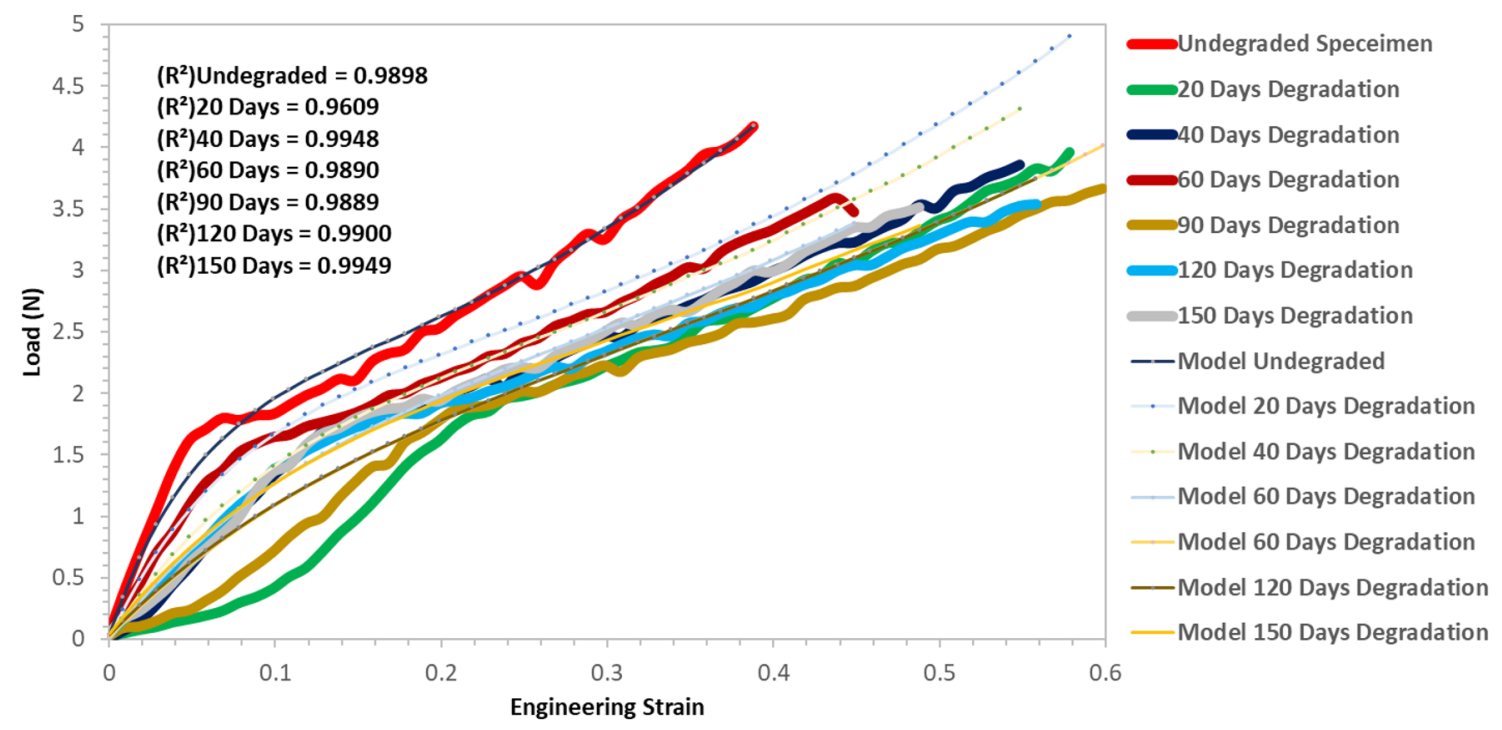

Fig. 18 Modelling the degradation behaviour of PLA fibres at a constant strain rate of $0.1 / \mathrm{s}$ by modified three-element standard solid model

\section{Conclusions}

PLA is one of the widely used polymer in the field of biomedical devices. It plays a significant role due to its ability to completely absorb within a human body in a specific period, which ranges from months to few years. Further, the ability to tailor their mechanical, microstructural, chemical and degradation properties for specific applications has catalysed an extensive amount of research, which led to use of these materials in innovative ways [24].

In the present work, during hydrolytic process, it is assumed the material has enough hydrophilicity and its diameter is small enough to produce a bulk erosion with negligible autocatalytic effects [70]. Hence, the degradation state in the specimens is assumed homogenous.

Since the mass loss is not observed in all degradation duration, it cannot be used as a degradation indicator [75]. Changes in the molar mass and strength are observed at an earlier stage for PLA, i.e. both properties can be used as an indicator of degradation. They observed a direct correlation between both properties from the experimental measurements [30]. Since the mechanical properties were the main interest in the present work, the mechanical properties decay was used to calibrate the hydrolytic damage law.

From the DSC experiment, the average crystallinity of PLA is around $61 \%$. Thus, for semi-crystalline material as the case with PLA, there coexistent two-phases, a crystalline and an amorphous phase which are non-homogeneous. The mobility of the amorphous phase decreases with the increase in degradation stages, and shrinkage in length of the fibres was observed at the end of degradation stages. However, the changes observed in the thermal properties were quite negligible to be considered as a relationship with the mechanical properties, and these thermal properties do not have a direct link with the degradation and mechanical properties.

Rate of degradation of PLA is observed to be slow because of which complete deterioration of mechanical as well as degradation properties was not observed in the period of 150 days at $37^{\circ} \mathrm{C}$. Force versus displacement graph of PLA was represented as a piecewise function following the methodology by Averett et al. This piece-wise function was able to replicate the graph as per the experimental data. Results obtained in this study are important as they will form the basis for further research in designing the LAD's for the orthopaedic application. These experimental results of undegraded PLA fibres were compared with the results obtained by Farrington et al. and Hossain et al. for PLA fibres and found to be in conjunction.

Evolution of the mechanical properties during degradation is a continuous process, which imposes serious complications in predicting the mechanical behaviour of these medical devices. Appropriate constitutive models incorporating hydrolytic damage are a convenient way to condense all relevant experimental data. Modified threeelement standard solid model was used for modelling the mechanical behaviour of PLA. Model parameters were found out by using method of least squares from uniaxial tensile test data. It was assumed that during each stage of degradation, stiffness parameters remains constant and 
only viscous parameters were changing at that degradation stage with the increase in strain rate. Thus, the viscous parameters were assumed as strain dependent, and the stiffness parameters were assumed to be dependent on degradation. Thus, the nonlinear viscoelastic model incorporated the hydrolytic degradation, through the stiffness parameters. Under these assumptions, the model was able to capture the shear thinning phenomena experienced by PLA fibres and stiffness decay during hydrolytic degradation.

These results are relevant for the design and development of new LAD's in the form of scaffolds. The aim is to construct LAD's, with better mechanical performance, improving the surgical outcomes on the repair of ligament tissue. Biodegradable polymers in case of the anterior crucial ligament $(\mathrm{ACL}$ ) should supply the load-bearing capabilities, strengthen the torn tissues during the rehabilitation period and subsequently lose the mechanical properties. Meanwhile, ligament must restore to its full capacity during rehabilitation.

Acknowledgements Anurag Singh wants to thank "EUPHRATES", an Erasmus Mundus project led by the University of Santiago de Compostela (Spain), for the PhD programme scholarship. Authors also want to thank Trevira, Germany, for supplying the PLA fibres, without which this work would not have possible. Diana Paiva thanks to project “LEPABE-2-ECO-INNOVATION"-NORTE-01-0145-FEDER-000005, funded by Norte Portugal Regional Operational Programme (NORTE 2020), under PORTUGAL 2020 Partnership Agreement, through the European Regional Development Fund (ERDF) for her postdoctoral fellowship. The authors also acknowledge project POCI-01-0145FEDER-006939 (Laboratory for Process Engineering, Environment, Biotechnology and Energy-UID/EQU/00511/2013), funded by European Regional Development Fund (ERDF) through COMPETE2020Programa Operacional Competitividade e Internacionalização (POCI), and by national funds through FCT—Fundação para a Ciência e a Tecnologia, which enabled the DSC measurements.

\section{Compliance with ethical standards}

Conflict of interest The authors declare that they have no conflict of interest.

\section{References}

1. Nanda R, Sasmal A, Nayak PL (2011) Preparation and characterization of chitosan-polylactide composites blended with Cloisite 30B for control release of the anticancer drug paclitaxel. Carbohydr Polym 83(2):988-994

2. Ulery BD, Nair LS, Laurencin CT (2011) Biomedical applications of biodegradable polymers. J Polym Sci B Polym Phys 49(12):832-864

3. Soares JS, Moore JE, Rajagopal KR (2008) Constitutive framework for biodegradable polymers with applications to biodegradable stents. ASAIO J 54(3):295-301

4. Bergström JS, Hayman D (2015) An overview of mechanical properties and material modeling of polylactide (PLA) for medical applications. Ann Biomed Eng 44(2):330-340
5. Velasco MA, Narváez-Tovar CA, Garzón-Alvarado DA (2015) Design, materials, and mechanobiology of biodegradable scaffolds for bone tissue engineering. Biomed Res Int 2015:729076

6. Soares PZ, João S (2015) A mathematical model for water uptake, degradation, erosion, and drug release from degradable polydisperse polymeric networks. December 2015

7. Casarin SA (2011) Study on in-vitro degradation of bioabsorbable polymers poly (hydroxybutyrate-co-valerate)-(PHBV) and poly (caprolactone)-(PCL). J Biomater Nanobiotechnol 02(03):207-215

8. Lakes RS (1998) Viscoelastic solids. CRC Press, Boca Raton

9. Bergstrom JS (2015) Mechanics of solid polymers: theory and computational modeling. Elsevier, Amsterdam

10. Netzsch (2016) Differential scanning calorimetry. Springer, Berlin, pp 1-24

11. Wunderlich B (1990) Thermal analysis. Academic Press, Cambridge

12. Schick C (2009) Differential scanning calorimetry (DSC) of semicrystalline polymers. Anal Bioanal Chem 395(6):1589-1611

13. Noah PMA, Ohandja LMA, Medjo RE, Chabira S, Ebanda FB, Ondoua PA (2016) Study of thermal properties of mixed (PP/ EPR)/ABS with five model compatibilizers. J Eng (US) 2016: Article ID 8539694

14. Vink ETH, Rábago KR, Glassner DA, Gruber PR (2003) Applications of life cycle assessment to NatureWorks ${ }^{\mathrm{TM}}$ polylactide (PLA) production. Polym Degrad Stab 80(3):403-419

15. Madhavan Nampoothiri K, Nair NR, John RP (2010) An overview of the recent developments in polylactide (PLA) research. Bioresour Technol 101(22):8493-8501

16. Murariu M, Dubois P (2016) PLA composites: from production to properties. Adv Drug Deliv Rev 107:17-46

17. Anderson JM, Shive MS (2012) Biodegradation and biocompatibility of PLA and PLGA microspheres. Adv Drug Deliv Rev 64(SUPPL):72-82

18. Li S, Vert M (2002) Biodegradation of aliphatic polyesters. In: Scott G (ed) Degradable polymers. Springer, Dordrecht, pp 71-131

19. Chen C-C, Chueh J-Y, Tseng H, Huang H-M, Lee S-Y (2003) Preparation and characterization of biodegradable PLA polymeric blends. Biomaterials 24(7):1167-1173

20. Takahashi K (2000) Melt/solid polycondensation of glycolic acid to obtain high-molecular-weight poly(glycolic acid). Polymer (Guildf) 41(24):8725-8728

21. Hayman D, Bergerson C, Miller S, Moreno M, Moore JE (2014) The effect of static and dynamic loading on degradation of PLLA stent fibers. J Biomech Eng 136:081006

22. Göpferich A (1996) Mechanisms of polymer degradation and erosion. Biomaterials 17(2):103-114

23. Muliana A, Rajagopal KR (2012) Modeling the response of nonlinear viscoelastic biodegradable polymeric stents. Int J Solids Struct 49(7-8):989-1000

24. Bergström JS, Hayman D (2015) An overview of mechanical properties and material modeling of polylactide (PLA) for medical applications. Ann Biomed Eng 44:330-340

25. Soares JS, Moore JE (2015) Biomechanical challenges to polymeric biodegradable stents. Ann Biomed Eng 44(2):560-579

26. Vieira AC, Guedes RM, Marques AT (2009) Development of ligament tissue biodegradable devices: a review. J Biomech 42(15):2421-2430

27. Kobayashi S, Yamadi S (2010) Strain rate dependency of mechanical properties of TCP/PLLA composites after immersion in simulated body environments. Compos Sci Technol 70(13):1820-1825

28. Breche $Q$ et al (2016) A non-linear viscoelastic model to describe the mechanical behavior's evolution of 
biodegradable polymers during hydrolytic degradation. Polym Degrad Stab 131:145-156

29. Laycock B et al (2017) Lifetime prediction of biodegradable polymers. Prog Polym Sci 71:144-189

30. Weir NA, Buchanan FJ, Orr JF, Farrar DF, Dickson GR (2004) Degradation of poly-L-lactide. Part 2: increased temperature accelerated degradation. Proc Inst Mech Eng Part H J Eng Med 218(5):321-330

31. Vieira AC, Vieira JC, Ferra JM, Magalhães FD, Guedes RM, Marques AT (2011) Mechanical study of PLA-PCL fibers during in vitro degradation. J Mech Behav Biomed Mater 4(3):451-460

32. Zhang $T$ et al (2019) Multiscale modelling for the heterogeneous strength of biodegradable polyesters. J Mech Behav Biomed Mater 90:337-349

33. Horan RL, Collette AL, Lee C, Antle K, Chen J, Altman GH (2006) Yarn design for functional tissue engineering. J Biomech 39(12):2232-2240

34. Altman GH et al (2002) Silk matrix for tissue engineered anterior cruciate ligaments. Biomaterials 23(20):4131-4141

35. Morais DS, Torres J, Guedes RM, Lopes MA (2015) Current approaches and future trends to promote tendon repair. Ann Biomed Eng 43(9):2025-2035

36. Ma PX (2004) Scaffolds for tissue fabrication. Mater Today 7(5):30-40

37. Laurent CP, Vaquette C, Liu X, Schmitt J-FF, Rahouadj R (2018) Suitability of a PLCL fibrous scaffold for soft tissue engineering applications: A combined biological and mechanical characterisation. J Biomater Appl 32(9):1276-1288

38. Hahn J et al (2019) Viscoelastic behavior of embroidered scaffolds for $A C L$ tissue engineering made of PLA and $P(L A-C L)$ after in vitro degradation. Int J Mol Sci 20(18):1-18

39. Breche $Q$ et al (2016) Mechanical behaviour's evolution of a PLA-b-PEG-b-PLA triblock copolymer during hydrolytic degradation. J Mech Behav Biomed Mater 60:288-300

40. Azevedo H, Reis R (2004) Understanding the enzymatic degradation of biodegradable polymers and strategies to control their degradation rate. In: Reis RL, Román JS (eds) Biodegradable systems in tissue engineering and regenerative medicine. CRC Press, Boca Raton

41. Cheung HY, Lau KT, Lu TP, Hui D (2007) A critical review on polymer-based bio-engineered materials for scaffold development. Compos Part B Eng 38(3):291-300

42. Saunders DW (1978) Creep and relaxation of nonlinear viscoelastic materials, vol 19. Courier Corporation, North Chelmsford

43. Ebert C, Hufenbach W, Langkamp A, Gude M (2011) Modelling of strain rate dependent deformation behaviour of polypropylene. Polym Test 30(2):183-187

44. Dean G, Crocker L, Read B, Wright L (2004) Prediction of deformation and failure of rubber-toughened adhesive joints. Int J Adhes Adhes 24(4):295-306

45. Drozdov AD (1996) Finite elasticity and viscoelasticity: a course in the nonlinear mechanics of solids. World Scientific, Singapore

46. Drozdov AD (1998) Viscoelastic structures: mechanics of growth and aging. Academic Press, Cambridge

47. Vieira AC, Guedes RM, Tita V (2015) Damage-induced hydrolyses modelling of biodegradable polymers for tendons and ligaments repair. J Biomech 48(12):3478-3485

48. Plaseied A, Fatemi A (2008) Deformation response and constitutive modeling of vinyl ester polymer including strain rate and temperature effects. J Mater Sci 43(4):1191-1199

49. Khan AS, Lopez-Pamies O, Kazmi R (2006) Thermo-mechanical large deformation response and constitutive modeling of viscoelastic polymers over a wide range of strain rates and temperatures. Int J Plast 22(4):581-601
50. Bird RB, Armstrong RC, Hassanger O (1987) Dynamics of polymeric liquids: fluid mechanics, vol 25. Wiley, Hoboken

51. Rossikhin Y, Shitikova M (2014) Centennial jubilee of Academician Rabotnov and contemporary handling of his fractional operator. Fract Calc Appl Anal 17(3):674-683

52. Provenzano P, Lakes R, Keenan T, Vanderby R Jr (2001) Nonlinear ligament viscoelasticity. Ann Biomed Eng 29(10):908-914

53. Drozdov AD, Viscoelasticity N (1998) A model of temporal polymeric networks in nonlinear viscoelasticity. Mech Res Commun 25(1):83-90

54. Schapery RA (1969) On the characterization of nonlinear viscoelastic materials. Polym Eng Sci 9(4):295-310

55. Makino K, Arakawa M, Kondo T (1985) Preparation and in vitro degradation properties of polylactide microcapsules. Chem Pharm Bull 33(3):1195-1201

56. Bauwens-Crowet C (1973) The compression yield behaviour of polymethyl methacrylate over a wide range of temperatures and strain-rates. J Mater Sci 8(7):968-979

57. Bauwens JC (1970) Yield condition and propagation of Lüders' lines in tension-torsion experiments on poly(vinyl chloride). J Polym Sci Part A 2 Polym Phys 8(6):893-901

58. Rana D, Sauvant V, Halary JL (2002) Molecular analysis of yielding in pure and antiplasticized epoxy-amine thermosets. J Mater Sci 37(24):5267-5274

59. Richeton J, Ahzi S, Daridon L, Rémond Y (2005) A formulation of the cooperative model for the yield stress of amorphous polymers for a wide range of strain rates and temperatures. Polymer (Guildf) 46(16):6035-6043

60. Bassett DC, Olley RH, AI Raheil IAM (1988) On crystallization phenomena in PEEK. Polymer (Guildf) 29(10):1745-1754

61. Cebe P, Hong S-D (1986) Crystallization behaviour of poly(etherether-ketone). Polymer (Guildf) 27(8):1183-1192

62. Supaphol P (2001) Crystallization and melting behavior in syndiotactic polypropylene: Origin of multiple melting phenomenon. J Appl Polym Sci 82(5):1083-1097

63. Richeton J, Ahzi S, Vecchio KS, Jiang FC, Adharapurapu RR (2006) Influence of temperature and strain rate on the mechanical behavior of three amorphous polymers: Characterization and modeling of the compressive yield stress. Int J Solids Struct 43(7-8):2318-2335

64. Brulé B, Halary JL, Monnerie L (2001) Molecular analysis of the plastic deformation of amorphous semi-aromatic polyamides. Polymer (Guildf) 42(21):9073-9083

65. Chen LP, Yee AF, Moskala EJ (1999) The molecular basis for the relationship between the secondary relaxation and mechanical properties of a series of polyester copolymer glasses. Macromolecules 32(18):5944-5955

66. Xiao C, Jho JY, Yee AF (1994) Correlation between the shear yielding behavior and secondary relaxations of bisphenol a polycarbonate and related copolymers. Macromolecules 27(10):2761-2768

67. Rietsch F, Bouette B (1990) The compression yield behaviour of polycarbonate over a wide range of strain rates and temperatures. Eur Polym J 26(10):1071-1075

68. Zhu KJ, Xiangzhou L, Shilin Y (1990) Preparation, characterization, and properties of polylactide (PLA)-poly(ethylene glycol) (PEG) copolymers: a potential drug carrier. J Appl Polym Sci 39(1):1-9

69. Djemai A, Gladden LF, Booth J, Kittlety RS, Gellert PR (2001) MRI investigation of hydration and heterogeneous degradation of aliphatic polyesters derived from lactic and glycolic acids: a controlled drug delivery device. Magn Reson Imaging 19(3-4):521-523

70. Grizzi I, Garreau H, Li S, Vert M (1995) Hydrolytic degradation of devices based on poly(dl-lactic acid) size-dependence. Biomaterials 16(4):305-311 
71. Averett RD, Realff ML, Michielsen S, Neu RW (2006) Mechanical behavior of nylon 66 fibers under monotonic and cyclic loading. Compos Sci Technol 66(11-12):1671-1681

72. Farrington DW, Lunt J, Davies S, Blackburn RS (2005) Poly (lactic acid) fibers. In: Blackburn RS (ed) Biodegradable and sustainable fibers. Woodhead Publishing, Cambridge, pp 191-220

73. Hossain KMZ, Parsons AJ, Rudd CD, Ahmed I, Thielemans W (2014) Mechanical, crystallisation and moisture absorption properties of melt drawn polylactic acid fibres. Eur Polym J 53(1):270-281
74. Bardenhagen SG, Stout MG, Gray GT (1997) Three-dimensional, finite deformation, viscoplastic constitutive models for polymeric materials. Mech Mater 25(4):235-253

75. Höglund A, Hakkarainen M, Edlund U, Albertsson AC (2010) Surface modification changes the degradation process and degradation product pattern of polylactide. Langmuir 26:378-383

Publisher's Note Springer Nature remains neutral with regard to jurisdictional claims in published maps and institutional affiliations. 